\title{
Linking fisheries, trophic interactions and climate: threshold dynamics drive herring Clupea harengus growth in the central Baltic Sea
}

\author{
Michele Casini $^{1, *}$, Valerio Bartolino ${ }^{1}$, Juan Carlos Molinero ${ }^{2}$, Georgs Kornilovs ${ }^{3}$ \\ ${ }^{1}$ Swedish Board of Fisheries, Institute of Marine Research, PO Box 4, 45321 Lysekil, Sweden \\ ${ }^{2}$ The Leibniz Institute of Marine Sciences (IFM-GEOMAR), West Shore Campus, Duesternbrooker Weg 20, \\ 24105 Kiel, Germany \\ ${ }^{3}$ Latvian Fish Resources Agency, Daugavgrivas Str. 8, 1048 Riga, Latvia
}

\begin{abstract}
How multiple stressors influence fish stock dynamics is a crucial question in ecology in general and in fisheries science in particular. Using time-series covering a $30 \mathrm{yr}$ period, we show that the body growth of the central Baltic Sea herring Clupea harengus, both in terms of condition and weight-at-age (WAA), has shifted from being mainly driven by hydro-climatic forces to an interspecific density-dependent control. The shift in the mechanisms of regulation of herring growth is triggered by the abundance of sprat, the main food competitor for herring. Abundances of sprat above the threshold of $\sim 18 \times 10^{10}$ ind. decouple herring growth from hydro-climatic factors (i.e. salinity), and become the main driver of herring growth variations. At high sprat densities, herring growth is considerably lower than at low sprat levels, regardless of the salinity conditions, indicative of hysteresis in the response of herring growth to salinity changes. The threshold dynamic accurately explains the changes in herring growth during the past 3 decades and in turn contributes to elucidate the parallel drastic drop in herring spawning stock biomass. Studying the interplay between different stressors can provide fundamental information for the management of exploited resources. The management of the central Baltic herring stock should be adaptive and take into consideration the dual response of herring growth to hydro-climatic forces and food-web structure for a sound ecosystem approach to fisheries.
\end{abstract}

KEY WORDS: Condition - Weight-at-age $\cdot$ WAA $\cdot$ Ecological threshold $\cdot$ Inter-specific densitydependence $\cdot$ Hydro-climate $\cdot$ Herring $\cdot$ Sprat $\cdot$ Ecosystem-based fisheries management $\cdot$ Alternative dynamics Resale or republication not permitted without written consent of the publisher

\section{INTRODUCTION}

Disentangling the combined effects of food-web structure and trophic interactions, climate changes and anthropogenic pressures (e.g. fishing) on population dynamics is of central importance for the understanding of ecosystem functioning, and thus the management of exploited resources. The quantification of the biotic and climatic effects on ecosystem dynamics, however, is often complicated by nonlinear relationships or discontinuous responses of populations and communities to the driving forces (Scheffer \& Carpenter 2003).

Herring Clupea harengus is a key species in the Baltic Sea ecosystem, as important prey for cod Gadus morhua (Bagge 1989) and a plankton-zoobenthos feeder (Casini et al. 2004). Moreover, herring is one of the most important commercial species in the area, heavily exploited by the 9 countries surrounding the Baltic Sea (EC 2008).

Since the late 1970s, the central Baltic herring stock has undergone a marked decline in stock size. How- 
ever, the drop in biomass has been more noticeable than the decrease in abundance (Fig. S1 in the Supplement at www.int-res.com/articles/suppl/m413p241_supp.pdf), which is partly explained by a parallel drastic decline in mean body weight (ICES 2009a). The decrease in individual herring weight was formerly hypothesised as a major effect of either climate-related hydrographic changes (i.e. decrease in salinity, Rönnkönen et al. 2004) or increased competition with the enlarged sprat Sprattus sprattus population (Cardinale \& Arrhenius 2000), both negatively affecting the main planktonic food for herring.

In the Baltic Sea it has been shown that both topdown and bottom-up controls (including hydroclimatic forces) can act simultaneously on different trophic levels (e.g. Alheit et al. 2005, Casini et al. 2008), but also that their relative strength can vary over time as a consequence of changes in the food-web structure (Casini et al. 2009). Specifically, zooplankton dynamics in the offshore areas is mainly regulated by hydrological forcing when the stock size of sprat is below a specific abundance threshold, whereas it is driven by sprat predation when the abundance of this major planktivore exceeds such a threshold (Casini et al. 2009). Similar dual ways of ecosystem functioning and trophic control have been also found for different species in other aquatic (Litzow \& Ciannelli 2007, Stige et al. 2009) as well as terrestrial (e.g. Wilmers et al. 2006) systems.

In this study we extend the concept of 'threshold dynamics' in the Baltic Sea from Casini et al. (2009) a step further, to investigate the body growth of the central Baltic herring. We show that the 2 apparently contrasting hypotheses of herring growth regulation (hydro-climatic factors and inter-specific densitydependence) are not mutually exclusive, providing evidence that the strength of the 2 forces on herring growth varies depending on food-web structure and interaction strength between competing species.

\section{MATERIALS AND METHODS}

Time-series of Baltic sprat stock abundance was retrieved from stock assessment official reports (ICES 2009a). Recently compiled herring biological data (individual total length, total weight and age) covering the period 1978 to 2008 were collected during the autumn international acoustic survey (ICES 2009b) by Latvia and Sweden in offshore areas of the central Baltic Sea (the Gotland Basin, ICES Subdivision 28, Fig. 1).

For the estimation of condition we used the doublelogarithmic length-weight regression, in line with previous studies on clupeid growth in the Baltic Sea (e.g.

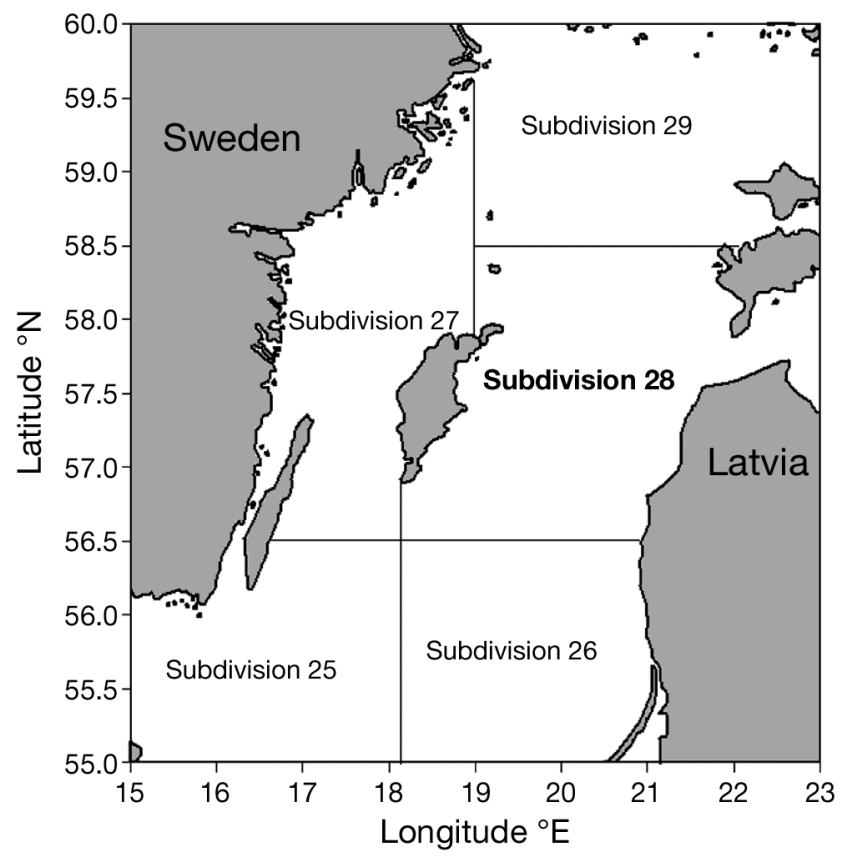

Fig. 1. Central Baltic Sea: ICES Subdivision 28 was the area of fish sampling

Möllmann et al. 2003, Casini et al. 2006). Condition was estimated from the year-specific $\ln (\mathrm{L})-\ln (\mathrm{W})$ regression as the weight in grams at the length of $180 \mathrm{~mm}$, which corresponded to the mean length of herring in our dataset.

Fish weight-at-age (WAA) is theoretically a result of forces acting over subsequent years from hatching to the date of collection. However, the trends in WAA were very similar among all age-classes, with simultaneous inter-annual variations (Fig. 2). This strongly suggests that changes in external conditions affect similarly the whole population at the same time. Therefore, for the purpose of our analyses we averaged the WAA of age 2+ fish, which represent the part of the population that will spawn in the following spring (i.e. at age 3+). At age 3+, central Baltic herring are fully reproductive (ICES 2009a) and therefore their mean body weight may have an effect on the stock recruitment success (Cardinale et al. 2009). Fish older than $5 \mathrm{yr}$ were excluded since in some years they were scarcely represented in our samples (<10 ind.).

Condition and WAA (hereafter referred as growth parameters) were used as indicators of the biological state of the fish at each specific year, and not as proxies for developmental/ontogenetic processes for which growth rate in length would have been more indicative (e.g. Winters \& Wheeler 1994).

To account for potential differences between countries in biological parameters (length and weight 

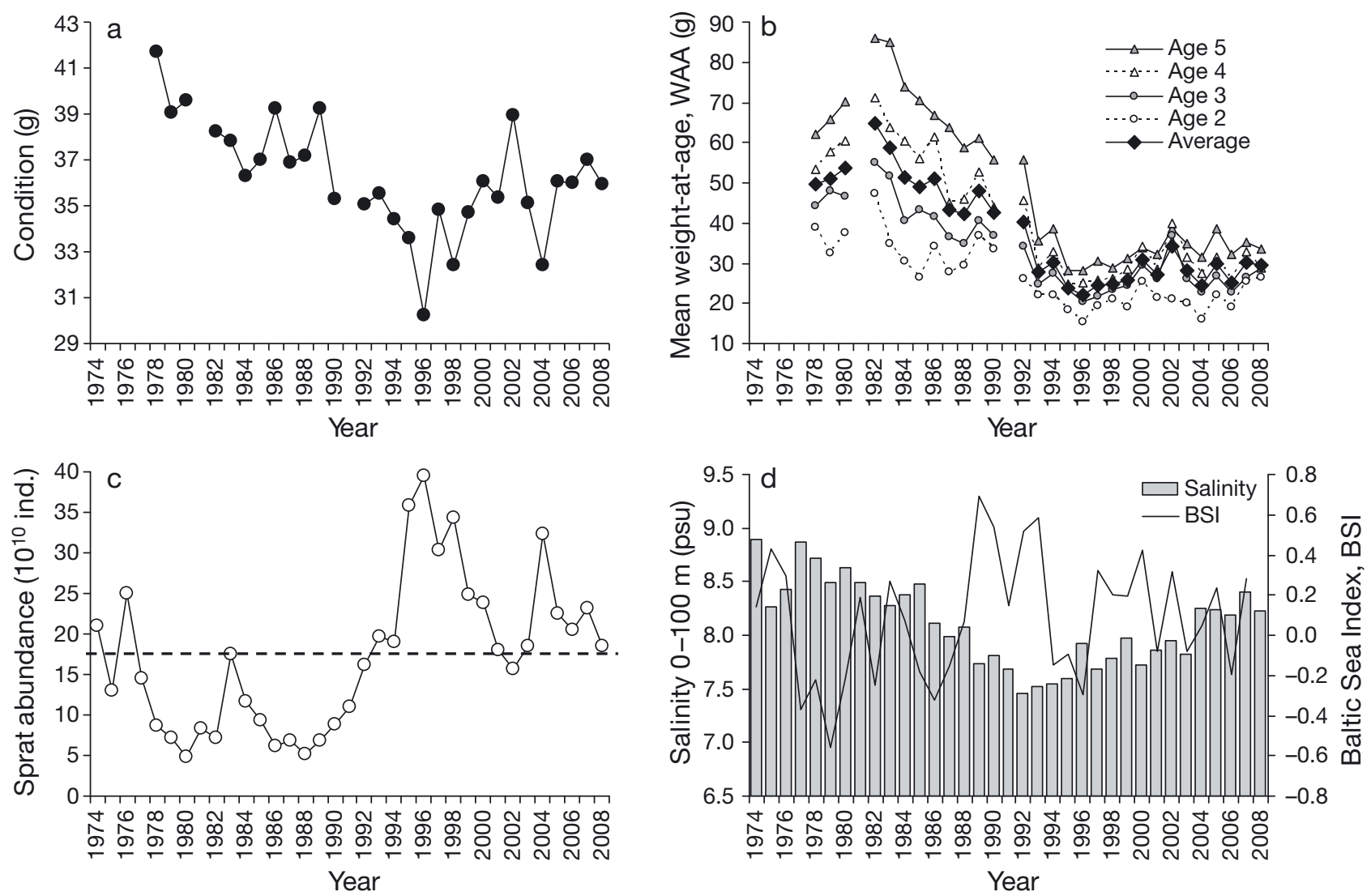

Fig. 2. Temporal trends of parameters used in the analyses: (a) herring condition, (b) herring weight-at-age (WAA), (c) sprat stock abundance, (d) salinity between 0 and $100 \mathrm{~m}$, and Baltic Sea Index, BSI (a proxy for the regional climate)

measurements as well as age estimations), and in turn growth calculation, a Generalized Linear Model (GLM) was used to predict the year effect on herring condition and WAA after scaling out the country effect. Condition data were normally distributed and, thus, the normal distribution was used in the GLM. For WAA, on the other hand, a Gamma distribution was preferred to account for the moderate skewness in the distribution of the data.

In the analyses we used growth data from ICES Subdivision 28, because this area was used in previous studies investigating herring growth (e.g. Möllmann et al. 2003, Casini et al. 2006) and ecosystem dynamics (Casini et al. 2008, 2009) and, therefore, constitutes a valid standpoint for comparison. Moreover, Subdivision 28 corresponds to the geographical centre of distribution of the herring and sprat stocks used in this study.

Salinity data for this area were provided by the Swedish Meteorological and Hydrological Institute (SMHI, freely available at www.smhi.se). The average of salinity in May and August integrated between 0 and $100 \mathrm{~m}$ depth (samples at surface and at $10 \mathrm{~m}$ depth intervals) was used in the analyses. Spring and sum- mer are the main feeding seasons for both herring and sprat in the central Baltic Sea (e.g. Szypuła et al. 1997), and spring is also the main reproduction period for the copepod Pseudocalanus spp., one of the main prey for both fish species (Möllmann et al. 2003, Casini et al. 2004). Therefore, spring-summer can be considered a critical period determining fish condition and WAA later in early autumn (Casini et al. 2006). Salinity is related to the Baltic Sea Index (BSI), a regional climate proxy closely coupled with the NAO (North Atlantic Oscillation). BSI is defined as the difference of normalized sea level pressure anomalies between Szczecin (Poland) and Oslo (Norway) (Lehmann et al. 2002). Positive values of both indices correspond to a dominance of westerlies over the Baltic and increased rainfall and runoff, whereas a negative index corresponds to easterlies (Hänninen et al. 2000, Lehmann et al. 2002).

The relationship between herring growth (in terms of condition and WAA) and the predictors was first analysed with Generalized Additive Models (GAMs). The following additive formulation was used:

$$
y=a+s_{1}\left(V_{1}\right)+\ldots+s_{n}\left(V_{n}\right)+\varepsilon
$$


where $a$ is the intercept, $s$ the thin plate smoothing spline function (Wood 2003), $V_{1} \ldots V_{n}$ the predictors and $\varepsilon$ the random error. As predictors, we used sprat stock abundance and salinity. These parameters were chosen because of their acknowledged importance for herring growth in the Baltic Sea, acting on the main planktonic prey for herring (Möllmann et al. 2003, Rönkkönen et al. 2004, Casini et al. 2006). We did not test for intra-specific density-dependence (i.e. effect of herring abundance on herring growth) as no evidence has been found for such relationship (Rönkkönen et al. 2004, Casini et al. 2006). The lack of intra-specific density-dependence is also supported by the absence of a negative relation between herring abundance and zooplankton in the offshore areas of the central Baltic Sea (Casini et al. 2008), that could be due to the omnivorous nature of herring which also feed on nektobenthos (Casini et al. 2004), reducing the interaction strength with zooplankton. Unfortunately, nektobenthos time-series covering our study period are not available for this area and could not be used in the growth models. The numerical dominance of sprat compared to herring in a large part of the study period (ICES 2009a) could also partly explain the lack of detectable intraspecific density-dependence within the herring population.

Furthermore, to test for the existence of a potential 'phase transition' (Litzow \& Ciannelli 2007) in the response of growth to the predictors, we applied a Threshold Generalized Additive Model (TGAM, Ciannelli et al. 2004) to condition and WAA. This kind of non-additive model can be formulated as:

$$
y=a+ \begin{cases}s_{1,1}\left(V_{1}\right)+\ldots+s_{1, n}\left(V_{n}\right)+\varepsilon & \text { for } V_{x}>t \\ s_{2,1}\left(V_{1}\right)+\ldots+s_{2, n}\left(V_{n}\right)+\varepsilon & \text { for } V_{x} \leq t\end{cases}
$$

where 2 specific additive formulations are adopted for different values of the threshold variable $V_{X}$. We tested the occurrence of a threshold on sprat abundance, under the assumption that the zooplankton community in the offshore Baltic Sea is dominated by environmental variability for low abundances of sprat, while it is driven by the dynamic of this pelagic fish when its abundance is high (Casini et al. 2009).

TGAMs are an extension of non-parametric regression techniques (Hastie \&Tibshirani 1990) and were chosen here for their ability to represent an abrupt change in the relationships between dependent and independent variables (i.e. a phase transition) at a specific threshold value. The threshold value was selected minimizing the Generalized Cross Validation score (GCV) of the whole model (Ciannelli et al. 2004). The searching algorithm runs the model for 100 possible threshold values between the 0.1 lower and the 0.9 upper quantiles. To evaluate the robustness of the esti- mated threshold, we performed a sensitivity analysis (Saltelli et al. 2000). Our objective was to test the dependency of the identified threshold value to the specific set of data and years available. We generated 1000 random replicates of the dataset, for different proportions of the original dataset. Then, a TGAM was fitted on each replicate and the corresponding threshold estimated. Residuals of the TGAMs were analysed to inspect for potential deviation from the normality assumption and other anomalies in the data or in the model fit (i.e. autocorrelation) using graphical methods (Cleveland 1993). Autocorrelation of the model residuals was examined using the autocorrelation function (ACF).

The normal distribution was used in the condition models, whereas a Gamma distribution was preferred for the WAA models due to the moderate skewness in the distribution of the data. Additive and threshold formulations were compared using the Akaike Information Criterion (AIC, Akaike 1973). To calculate the AIC for TGAMs, an extra penalty was introduced to account for the threshold parameter.

Additionally, an estimate of the significance of the threshold was obtained through a wild bootstrap approach (Mammen 1993). In this case, a null scenario of no-threshold effect was simulated reshuffling the threshold variable. Then, the same threshold model formulation was fitted and the penalized maximum log-likelihood (PML) of the model was calculated. This procedure was repeated 1000 times reshuffling the threshold variable in each bootstrap sample. In this way we obtained a reference distribution of the PML for the null scenario of no-threshold effect. Finally, the bootstrap estimate of the p-value for the threshold was calculated as the percentage of the PML values of the reference distribution for the null scenario that was larger than the original model PML.

The strength of the link between herring growth and sprat abundance (as well as salinity) in the 2 configurations identified by the TGAM was also assessed, by quantifying the probability density distribution of the correlation coefficients obtained by bootstrap resampling (Casini et al. 2009). This analysis involved a random pairwise sampling with replacement where each time-series was resampled 5000 times. The number of elements in each bootstrap sample equals the number of elements in the original dataset. The probability density distribution of the corresponding correlation coefficients was then computed using nonparametric kernel smoothing (Casini et al. 2009). In the simple linear correlation analyses, the potential occurrence of temporal autocorrelation in the growth time-series was tested in the 2 configurations using the autocorrelation function (ACF). 


\section{RESULTS}

Time-series of herring condition and WAA are presented in Fig. 2a,b. Condition showed a continuous decline from the late 1970s, reaching a minimum in 1996. Thereafter, herring condition increased, although oscillating at relatively low levels. WAA showed a similar pattern, except the decline started some years later than for condition, and the increase after 1996 was not as marked as for condition. WAA trends showed a tight covariation among all ageclasses, with inter-annual changes coincident for the whole population. Sprat stock was mostly at low levels between the late 1970s and the early 1990s, followed by a drastic increase that peaked in the years 1995 to 1996. Subsequently, the sprat stock has oscillated at relatively high levels (Fig. 2c). Salinity between 0 to $100 \mathrm{~m}$ showed a constant decrease from the 1970s to the early 1990s, followed by a steady increase, and eventually reached values almost as high as at the beginning of the time-series (Fig. 2d). Salinity was significantly correlated with the winter Baltic Sea Index ( $\mathrm{r}=-0.43, \mathrm{p}=0.012$; after correcting for temporal autocorrelation by first-order differencing, $\mathrm{r}=-0.38, \mathrm{p}=$ 0.028), evidencing the strong influence of atmospheric oscillations on the hydrological processes in the Baltic Sea (Hänninen et al. 2000, Lehmann et al. 2002).

In general, both for the GAMs and TGAMs, the effect of sprat abundance on herring growth was stronger than the effect of salinity (Table 1). The 2 predictors were significant in all the models, except salinity in the GAM for WAA. Threshold models performed generally better than additive formulations both in terms of deviance explained and AIC (Table 1). However, the improvements including a threshold were more evident for the WAA model than for the condition model, which showed a weaker non-additivity in the dynamics (Table 1), as also shown by the shallower minimum in the GCV profile (see Figs. 3b
\& 4b). The PML calculated on the original data was smaller than the lower $5 \%$ of the PML distribution for the bootstrap under the no-threshold null hypothesis in both the condition and WAA models (Fig. S2 in the Supplement). Consequently, the thresholds identified were considered statistically significant for both growth parameters. In addition, the same significant threshold value of $\sim 18 \times 10^{10}$ sprat individuals was obtained for both the response variables (Table 1). For sprat abundances lower than the identified threshold (low-sprat configuration), salinity showed a significant positive relationship with both condition and WAA. In contrast, for sprat abundances higher than the identified threshold (high-sprat configuration), a significant negative effect of sprat on herring growth was found (Table 1, Figs. 3c,d \& 4c,d). The TGAM formulation correctly captured the general pattern of herring condition along the whole time period investigated (Fig. 3a). The model performed better during the second half of the time series, tightly modelling the wide inter-annual fluctuations that characterized herring condition. The TGAM formulation well described the rapid drop in WAA observed in the mid 1990s and the following fluctuations around values almost half of those observed at the beginning of the time-series (Fig. 4a). The model underestimated 1982 to 1983 values and overestimated the peak in WAA observed in 2002. The residuals of the TGAMs did not violate the normality assumption and did not present temporal autocorrelation (Fig. S3 in the Supplement).

The sensitivity analysis showed that a decrease in the dataset size did not affect the median of the estimated threshold in the TGAMs (Fig. 5). A reduction of the dataset size down to $72 \%$ of the original size had only minor effect on the precision of the threshold estimate in the WAA model. A sensible loss in the precision of the estimate was observed only for levels $<70 \%$ of the dataset size, with an asymmetric dispersion

Table 1. Generalized Additive Model (GAM) and Threshold Generalized Additive Model (TGAM) analyses. For each model, deviance explained (Dev. Expl.), Akaike Information Criterion (AIC) and no. observations (n) are given. For each predictor, effective degrees of freedom (edf) and significance value ( $\mathrm{p}$ ) are provided. For TGAMs, threshold value (t) and no. of observations above and under the threshold are also given $(\mathrm{n}(\mathrm{t}))$. WAA: weight-at-age

\begin{tabular}{|c|c|c|c|c|c|c|c|c|c|c|}
\hline Model & Herring response & Threshold (t) & Dev. Expl. & AIC & $\mathrm{n}$ & Factors & $F$ & edf & $\mathrm{p}$ & $\mathrm{n}(\mathrm{t})$ \\
\hline \multirow[t]{4}{*}{ GAM } & \multirow[t]{2}{*}{ Condition } & \multirow[t]{2}{*}{ - } & \multirow[t]{2}{*}{77.3} & \multirow[t]{2}{*}{102.07} & \multirow[t]{2}{*}{29} & Salinity & 3.55 & 2.22 & 0.0295 & - \\
\hline & & & & & & Sprat & 15.13 & 1.72 & $<0.0001$ & - \\
\hline & \multirow[t]{2}{*}{ WAA } & \multirow[t]{2}{*}{-} & \multirow[t]{2}{*}{79.0} & \multirow[t]{2}{*}{189.90} & \multirow[t]{2}{*}{29} & Salinity & 1.95 & 1.71 & 0.149 & - \\
\hline & & & & & & Sprat & 18.79 & 2.05 & $<0.0001$ & - \\
\hline \multirow[t]{4}{*}{ TGAM } & \multirow[t]{2}{*}{ Condition } & \multirow[t]{2}{*}{17.85} & \multirow[t]{2}{*}{81.4} & \multirow[t]{2}{*}{101.67} & \multirow[t]{2}{*}{29} & Salinity for sprat $<t$ & 5.75 & 2.76 & 0.0045 & 16 \\
\hline & & & & & & Sprat for sprat $\geq t$ & 22.14 & 2.82 & $<0.0001$ & 15 \\
\hline & \multirow[t]{2}{*}{ WAA } & \multirow[t]{2}{*}{17.85} & \multirow[t]{2}{*}{88.8} & \multirow[t]{2}{*}{173.96} & \multirow[t]{2}{*}{29} & Salinity for sprat $<\mathrm{t}$ & 9.86 & 1.00 & 0.0044 & 16 \\
\hline & & & & & & Sprat for sprat $\geq t$ & 47.33 & 2.95 & $<0.0001$ & 15 \\
\hline
\end{tabular}



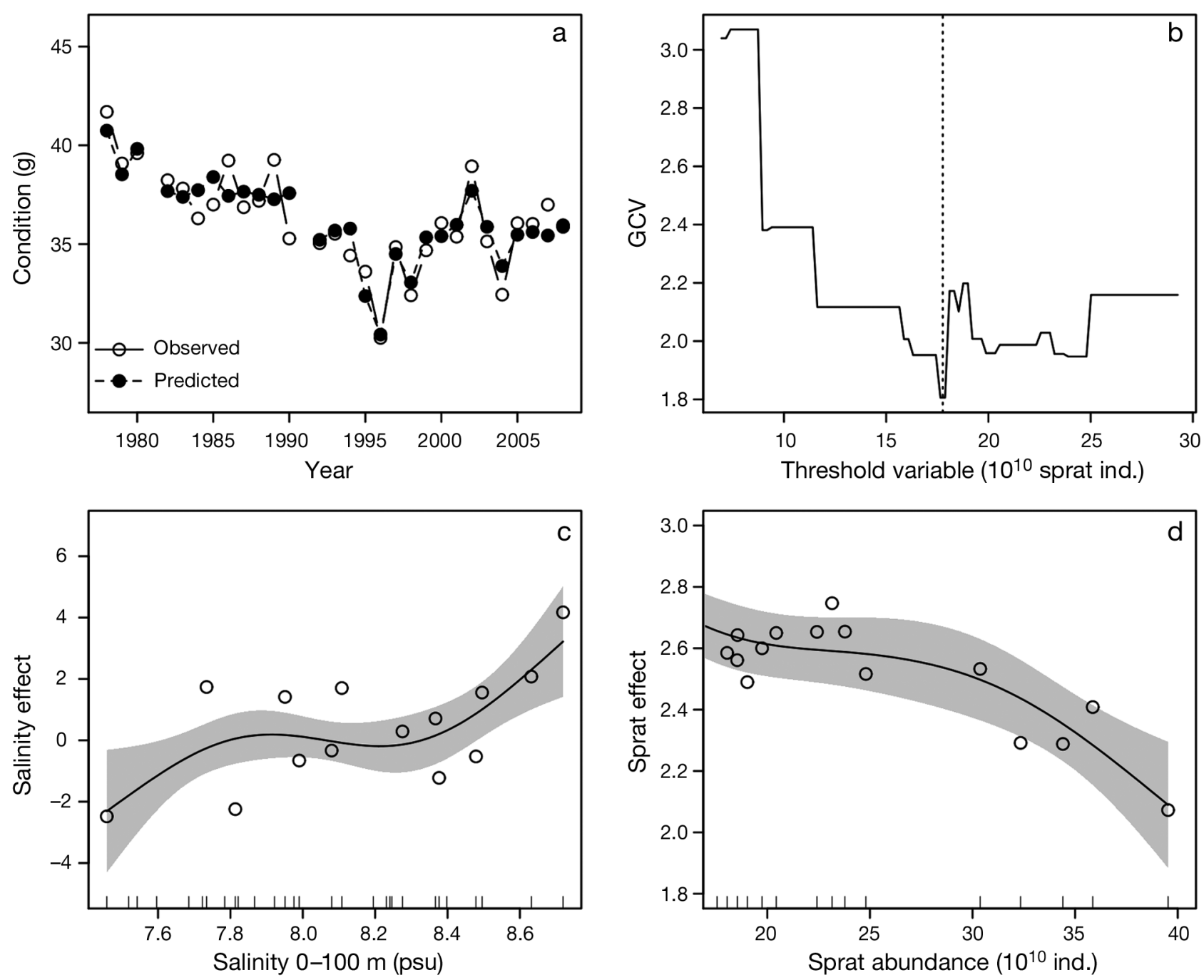

Fig. 3. Threshold Generalized Additive Model (TGAM) for herring condition. (a) Time-series of observed values and values predicted by TGAM, (b) Generalized Cross Validation (GCV) score profile as function of threshold variable (sprat abundance) with vertical dotted line = estimated threshold, (c) effect (unitless) of salinity on condition, (d) effect of sprat abundance on condition. Grey-shaded regions represent $95 \%$ confidence intervals

towards low threshold estimates. The sensitivity analysis on the condition model showed a more symmetric dispersion but poorer stability in the estimates of the threshold. Threshold estimates showed a visible dispersion already omitting $7 \%$ of the original condition dataset (Fig. 5).

The linear relationships between variations in herring growth and the predictors (salinity and sprat abundance) in the 2 configurations identified by the TGAM are shown in Fig. 6 (condition) and Fig. 7 (WAA). Considering the whole period, the analysis evidenced a strong negative Pearson's correlation coefficient between sprat abundance and growth parameters. However, the analysis of the relationship in the low-sprat configuration did not provide statistical support that variations in herring growth are related to sprat abundance, as illustrated by the simple linear correlations and the probability density distribution of correlations coefficients (Figs. 6a,c \& 7a,c). On the other hand, in the high-sprat configuration, the link was significantly enhanced and herring growth was closely coupled to sprat variations (Figs. 6a,c \& 7a,c). Reversed results were found in the assessment of the link between herring growth and salinity. In fact, considering the whole period, the analysis showed a positive Pearson's correlation coefficient, which increased in the low-sprat configuration (Figs. 6b,d \& 7b,d). In contrast, in the high-sprat configuration, no relationship between salinity and herring growth was noticeable (Figs. 6b,d \& 7b,d). Herring growth showed lower values in the high-sprat configuration than in the lowsprat configuration, regardless of the salinity level. In 

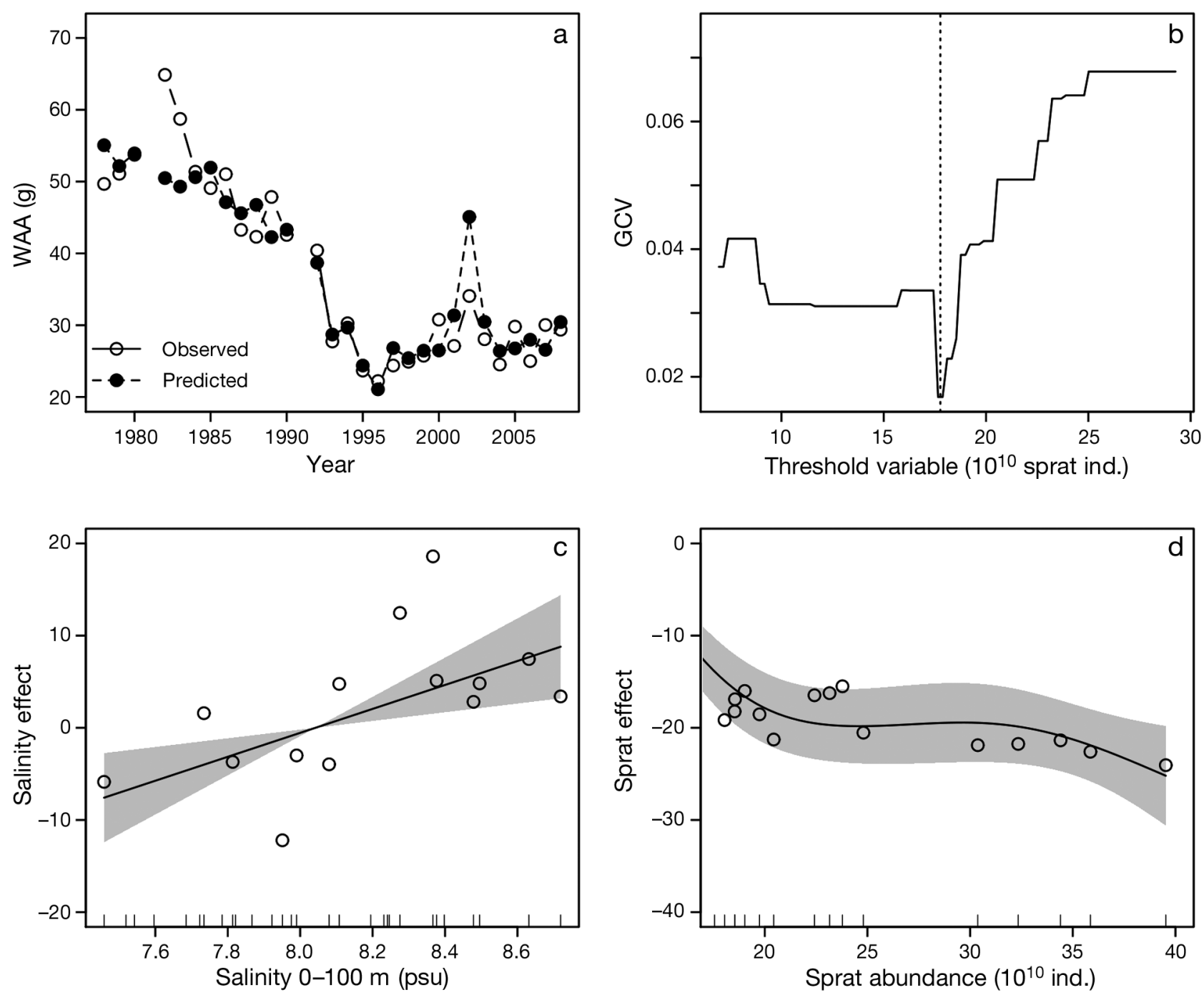

Fig. 4. TGAM for herring WAA. (a) Time-series of observed values and values predicted by TGAM, (b) GCV profile as function of threshold variable (sprat abundance) with vertical dotted line = estimated threshold, (c) effect of salinity on WAA, (d) effect of sprat abundance on WAA. Grey-shaded regions represent $95 \%$ confidence intervals

general, the improvement of the relationship between growth and sprat abundance in the high-sprat configuration (and between growth and salinity in the lowsprat configuration) was more evident for herring WAA than condition, as shown by the Pearson's correlation coefficients and their probability density distributions. The growth time-series did not present temporal autocorrelation in either of the 2 configurations (Fig. S4 in the Supplement).

\section{DISCUSSION}

In this study, we have shown that the main factors driving herring growth in the central Baltic Sea may switch following changes in other key food-web com- ponents. Specifically, we found that the dominant factors affecting variations in the growth of herring switched from salinity to inter-specific competition depending on the size of the sprat population. Therefore, during the past 3 decades, a combination of changes in hydro-climatic factors and trophic interactions after the sprat outburst, has led to a drastic reduction in the individual growth of herring.

The factors affecting the body growth of other herring populations worldwide have been intensively investigated. These factors range from internal population control, e.g. intra-specific density-dependence (Winters \& Wheeler 1994, Tanasichuk 1997, Shin \& Rochet 1998, Melvin \& Stephenson 2007), physical forcing as wind-induced turbulence (Shin \& Rochet 1998), to temperature (Watanabe et al. 2008) and/or 


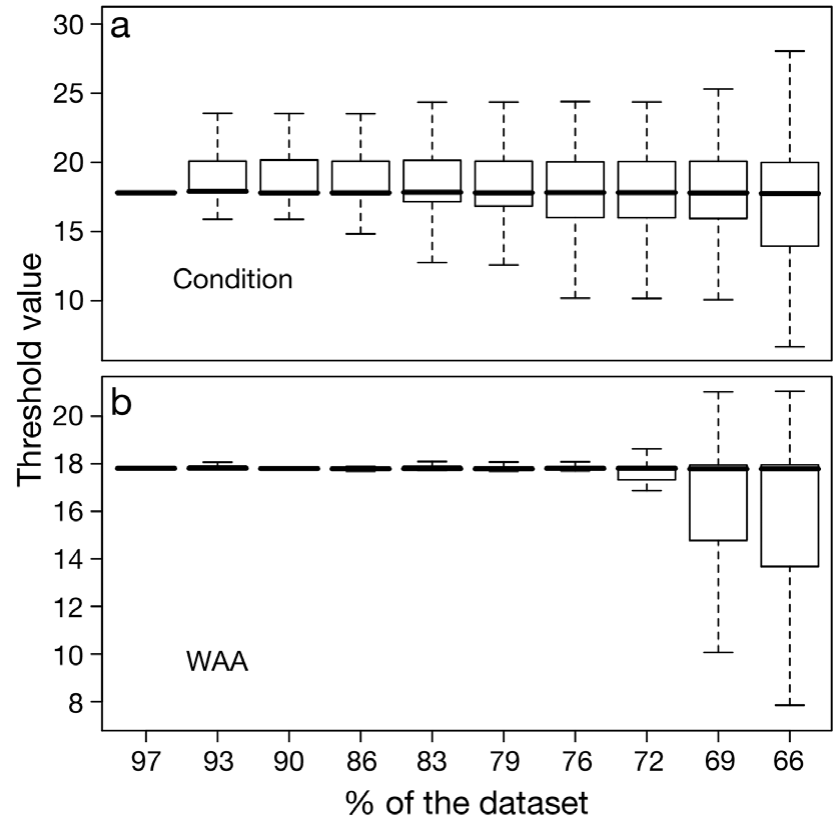

Fig. 5. Sensitivity analysis for (a) herring condition and (b) WAA. Boxplot of threshold values estimated sampling different proportions of original dataset (randomly sampling from 97 to $66 \%$ of the time-series). Bold lines identify the median, and box-whiskers = approximate 2 -side $95 \%$ confidence interval and first and third quartiles
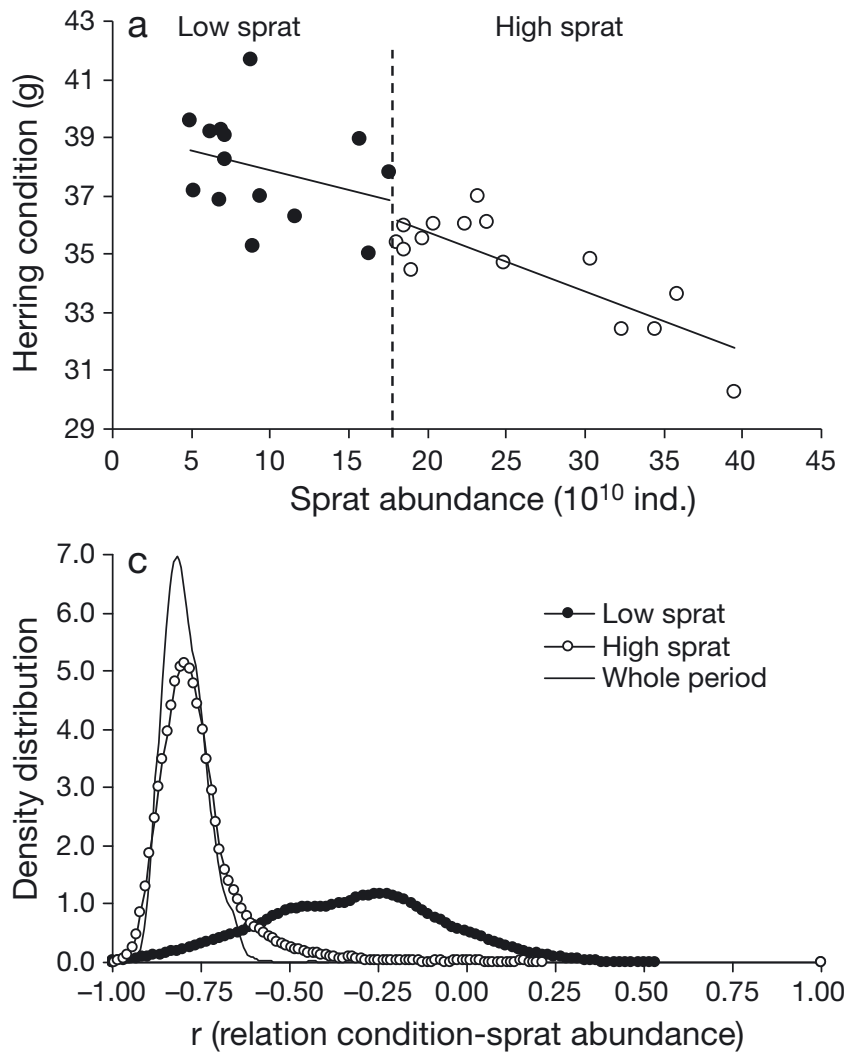

anthropogenic stress as fishery-related size selection (Wheeler et al. 2009). Density-dependence and hydroclimatic forces have also been suggested to act at different temporal (Heath et al. 1997) and spatial (Husebø et al. 2007) scales.

Compared to other herring stocks, the central Baltic Sea herring population inhabits an enclosed brackish environment, which makes organisms particularly sensitive to large salinity variations determined by climate-mediated irregular water inflows from the North Sea and precipitation (Voipio 1981, Lehmann et al. 2002). Moreover, the large diet overlap between herring and sprat in this region (Casini et al. 2004) produces a strong inter-specific feeding competition among clupeids. Accordingly, the growth of the central Baltic Sea herring has been previously linked to salinity variations and sprat stock size (Möllmann et al.

Fig. 6. Alternative dynamics in regulation mechanism of herring condition. (a) Relationships between sprat abundance and herring condition in the 2 configurations. Low-sprat: $\mathrm{r}=$ $-0.56, p=0.27$; high-sprat: $r=-0.82, p=0.00022$; whole period: $r=-0.82, p<0.0001$; (b) relationships between salinity and herring condition in the 2 configurations. Low-sprat: $\mathrm{r}=$ $0.58, \mathrm{p}=0.030$; high-sprat: $\mathrm{r}=0.22, \mathrm{p}=0.43$; whole period: $\mathrm{r}=$ $0.54, \mathrm{p}=0.0024$. Nos. (each point) $=$ observation year. $(\mathrm{c}, \mathrm{d})$ Density distribution of correlation coefficients between herring condition and sprat abundance, as well as salinity, in the 2 configurations and whole study period
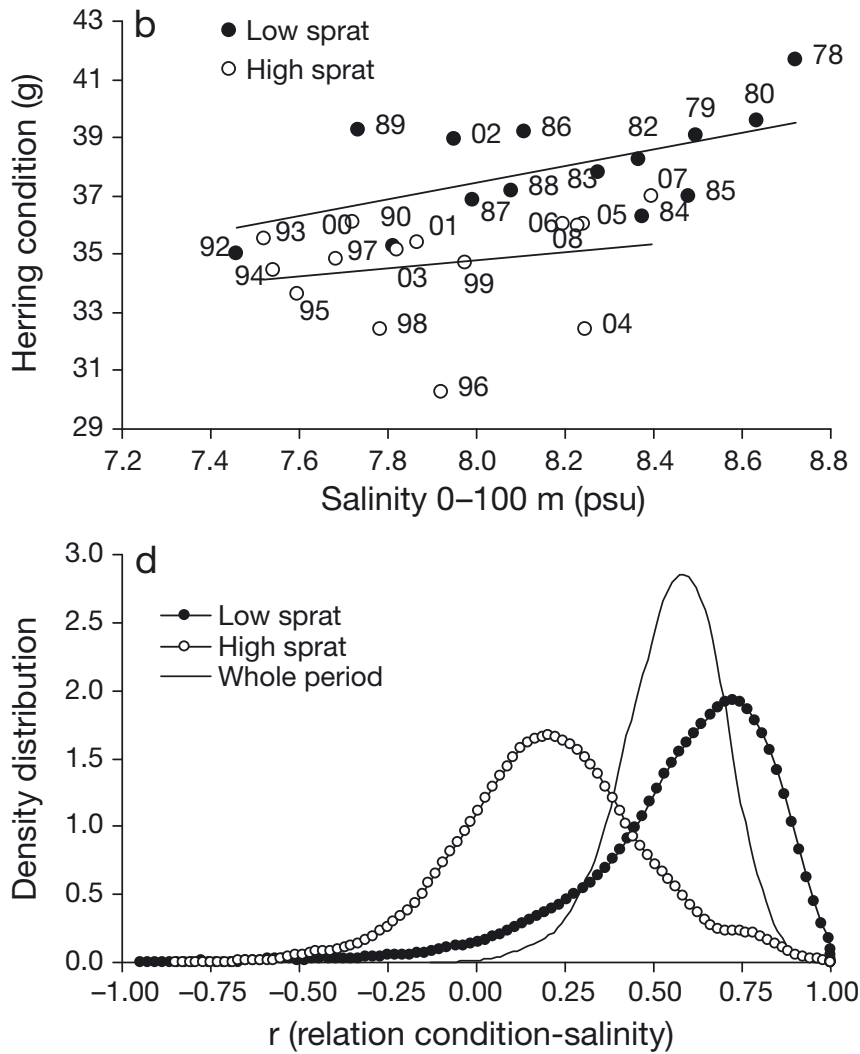

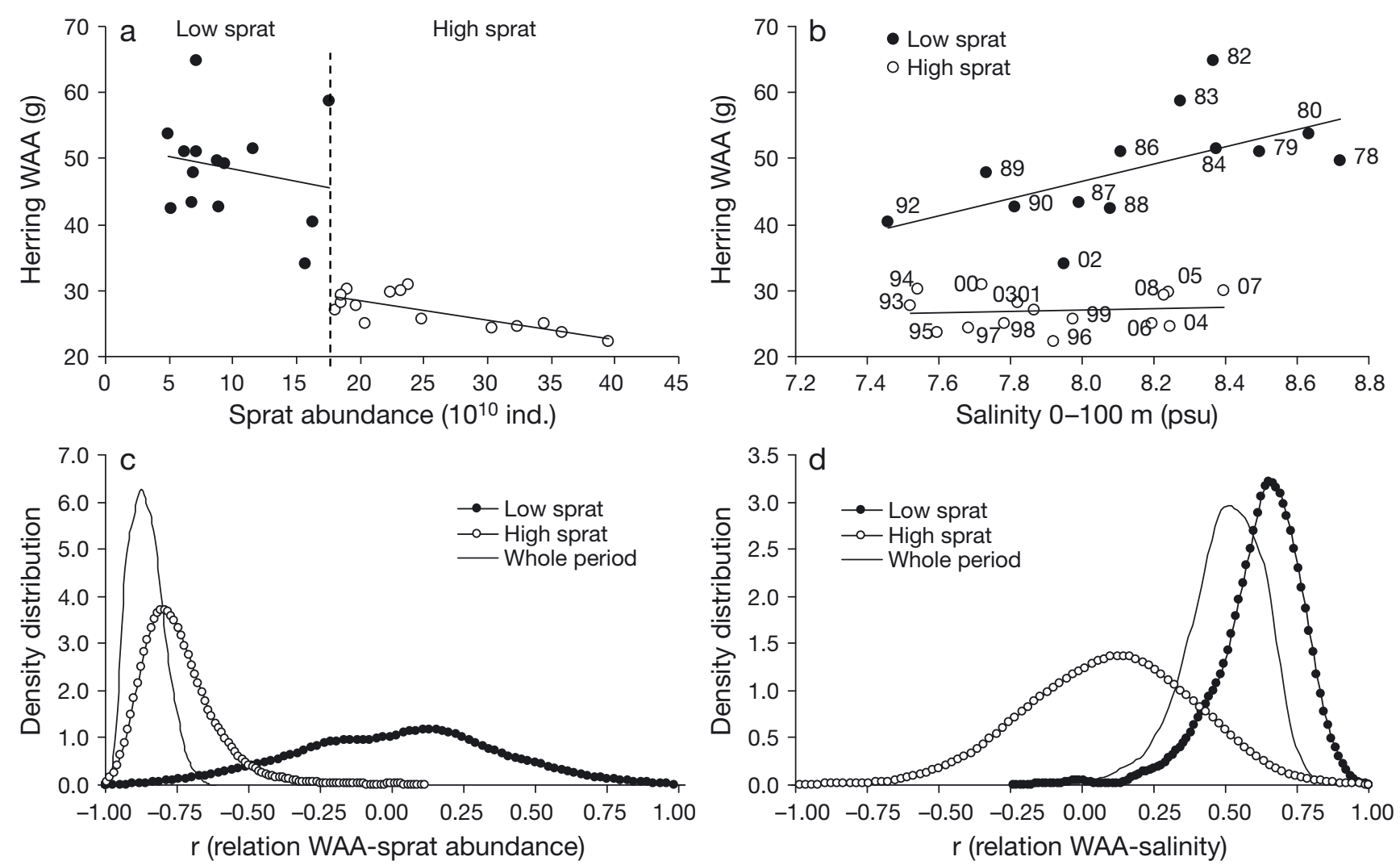

Fig. 7. Alternative dynamics in regulation mechanism of herring WAA. (a) Relationships between sprat abundance and herring WAA in the 2 configurations. Low-sprat: $r=-0.20, p=0.49$; high-sprat: $r=-0.76, p=0.001$; whole period: $r=-0.81, p<0.0001$; (b) relationships between salinity and herring WAA in the 2 configurations. Low-sprat: $r=0.60, p=0.032$; high-sprat: $r=0.11$, $p=0.69$; whole period: $r=0.53, p=0.0031$. Nos. (each point) $=$ observation year. $(\mathrm{c}, \mathrm{d})$ Density distribution of the correlation coefficients between herring WAA and sprat abundance, as well as salinity, in the 2 configurations and whole study period

2003, Casini et al. 2006), both factors acting on the abundance of one of the main preys for herring, the copepod Pseudocalanus spp. In particular, while the growth and reproductive performance of this zooplankter are enhanced by high salinity, sprat predation can operate a top-down control on this food resource (Möllmann \& Köster 2002, Renz \& Hirche 2006). Our results add to this general ecological understanding a crucial aspect, showing that the relative strength of the 2 main drivers (i.e. salinity and inter-specific competition) on herring growth may switch depending on the stock size of the sprat, the main planktivorous fish in the offshore areas of the central Baltic Sea. We specifically identified an ecological threshold of $\sim 18 \times 10^{10}$ sprat individuals which separated one low-sprat configuration characterized by a close link between herring growth and salinity variations, and one high-sprat configuration in which herring growth appears decoupled from salinity and becomes strongly controlled by inter-specific density-dependence.

The ecological explanation of this switch in the main regulatory mechanisms of herring growth is provided by Casini et al. (2009) who showed that the external drivers of zooplankton dynamics switch from hydroclimatic forcing to predation pressure depending on the population size of sprat. Also for zooplankton, the shift from one regulation mechanism to the other is triggered when the sprat population exceeds the threshold of $\sim 17 \times 10^{10}$ sprat individuals (Casini et al. 2009), very close to the threshold found in our study. In particular, at low levels of sprat population, Pseudocalanus spp. appears to be driven by salinity variations, a link that is disrupted when the abundance of sprat exceeds the ecological threshold (Casini et al. 2009).

The evidence provided by our investigation in combination with Casini et al. (2009) underlines that in low diverse systems, as the Baltic Sea, variations in key species such as sprat can have implications for ecosystem functioning detectable across trophic levels. Specifically, although salinity is an important factor for herring condition and WAA (e.g. Flinkman et al. 1998, Möllmann et al. 2003, Rönnkönen et al. 2004), our study provides evidence that food-web interactions, i.e. competition with sprat, can dampen the positive effect of high salinities, and become the main regulator of herring growth. This is exemplified by the increase 
in salinity from the beginning of the 1990s, which was not translated into the expected increase in herring growth (especially WAA), despite the high biomass of the primary producers (Casini et al. 2008). This demonstrates the occurrence of a discontinuous pattern (i.e. hysteresis) in the response of herring growth to salinity variations (Fig. 8) that may be indicative of alternative stable states in the system (Scheffer \& Carpenter 2003). The shift between the 2 configurations during the past 3 decades has been triggered by the dramatic increase in the sprat stock, which has been linked before to predation release from cod (Casini et al. 2008) whose stock decreased due to high fishing pressure (ICES 2009a) and adverse hydro-climatic factors (i.e. low salinity and anoxic conditions in the deep waters) (Köster et al. 2005). However, the rise in temperature, which enhances sprat egg and larval survival, has also contributed to the sprat stock increase (Nissling 2004, Alheit et al. 2005).

The occurrence of shifts in the functioning of marine ecosystems has been generally seldom reported, although some examples exist (e.g. Hunt et al. 2002, Ciannelli \& Litzow 2007, Stige et al. 2009). In the Gulf of Alaska it was found that the Pacific cod-prey interaction is either top-down or bottom-up regulated depending on temperature conditions and community state (Litzow \& Ciannelli 2007). Hunt et al. (2002) also suggested that temperature and ice dynamics modulate the strength of top-down and bottom-up forces on the recruitment of walleye pollock population Theragra chalcogramma in the Barents Sea. Stige et al. (2009), on the other hand, showed for the Barents Sea that at low densities of planktivorous fish (capelin Mallotus villosus) the climate forcing on zooplankton is stronger, similar to what we found in our study for herring growth. In our study, however, we also indicate a putative ecological threshold $\left(\sim 18 \times 10^{10}\right.$ ind. sprat $)$

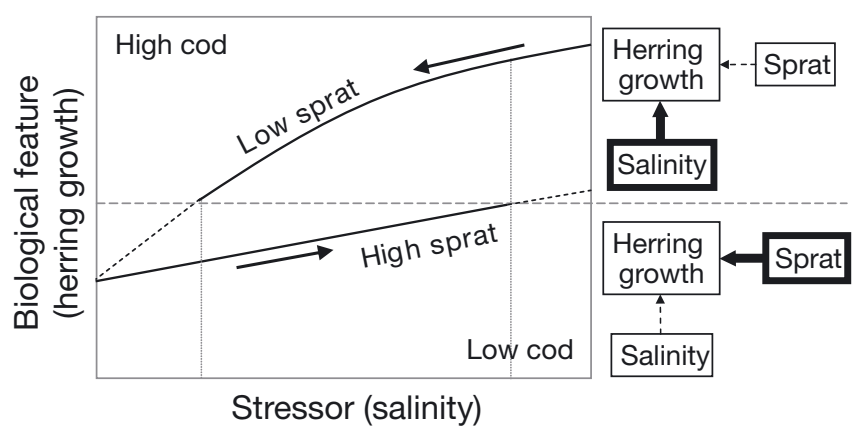

Fig. 8. Discontinuity (hysteresis) in the response of herring growth to variations in salinity. In low-sprat configuration, salinity explains changes in herring growth, whereas in high-sprat configuration the link between herring growth and salinity becomes weaker and inter-specific densitydependence becomes the main factor affecting herring growth responsible for the shift in the control of herring growth.

The threshold dynamic evidenced in our study by the TGAMs was more evident for herring WAA than condition, as shown by all the statistics used in the analyses. Although at the moment we do not have robust elements to provide a comprehensive explanation for this difference, the common threshold identified indicates that common mechanisms are behind the threshold dynamic of both growth parameters. It is worth noting that using additive models (GAMs) sprat abundance was the main explanatory factor, whereas salinity appeared of minor importance. Also using TGAMs, the strength of the relationship between sprat abundance and herring growth in the high-sprat configuration appeared higher than the relationship between salinity and herring growth in the low-sprat configuration. These considerations point to that, while a significant threshold was identified by our analyses, the density-dependent mechanism seems overall to have been the major regulator of herring growth during the past 3 decades.

The direct effect of fishing on the body size of target organisms has been shown by several studies (Shin et al. 2005). Also for the central Baltic Sea, it may be suggested that the high fishing mortalities during the 1980s and 1990s (ICES 2009a) have contributed to the reduction in the mean size of herring by selecting the larger individuals (e.g. Vainikka et al. 2009). However, the increase in fishing mortality could be partly an effect, and not only a cause, of the decrease in individual herring size (ICES 2009a). In fact, for a given catch in biomass, a decrease in fish individual weight would imply a higher number of fish caught every year. We opted, therefore, not to introduce fishing mortality as a potential predictor in our analyses. The question whether changes in fishing mortality are mainly a cause, or a result, of the variations in herring mean size is worth further investigation.

The central Baltic herring stock decreased steadily from the end of the 1970s (ICES 2009a). The drop in WAA and condition of the spawners could have indirectly contributed to the general decrease in the herring stock, by hampering the population recruitment success (Cardinale et al. 2009), likely through reduced fecundity and hatching success of the eggs (Laine \& Rajasilta 1999). The decrease in herring body growth also directly contributes to explain the sharper decrease in herring spawning stock biomass, than in stock abundance, since the early 1980s (Fig. S1 in the Supplement). This is because a decrease in the mean weight is automatically translated into a reduction in biomass, for comparable levels of abundance. However, the change in age structure of the spawning population towards a relatively higher abundance of 
younger spawners (ICES 2009a) has likely also contributed to the drastic decrease in spawning stock biomass.

The results presented here have important implications for an ecosystem-approach to fisheries management. The threshold in the mechanisms of regulation of herring growth implies that effective management should take in consideration both hydro-climatic circumstances and food-web structure, and be adaptive to their variations with prompt management actions. We have specifically detected here a clear-cut and easy-to-understand threshold value which could be used to reach the goal of a healthy central Baltic herring stock. The restraint of the sprat population below the abundance threshold would release herring from inter-specific competition and enhance herring growth, increasing spawning stock biomass and stock reproductive potential. The best way to achieve this goal is to allow the Baltic cod stock to recover to a level capable of controlling the sprat population.

Acknowledgements. This paper is dedicated to the memory of our colleague and dear friend Johan Modin, who inspired Fig. 8.

\section{LITERATURE CITED}

Akaike $H$ (1973) Information theory and an extension of maximum likelihood principle. In: Petrov BN, Csáki F (eds) Proc Sec Int Symp Info Theory. Akademia Kiado, Budapest

Alheit J, Möllmann C, Dutz J, Kornilovs G, Loewe P, Mohrholz V, Wasmund N (2005) Synchronous ecological regime shifts in the central Baltic and the North Sea in the late 1960s. ICES J Mar Sci 62:1205-1215

Bagge O (1989) A review of investigations of the predation of cod in the Baltic. Rapp P-V Reun Cons Int Explor Mer 190: 51-56

> Cardinale M, Arrhenius F (2000) Decreasing weight-at-age of Baltic herring (Clupea harengus) between 1986 and 1996: a statistical analysis. ICES J Mar Sci 57:882-893

Cardinale M, Möllmann C, Bartolino V, Casini M and others (2009) Effect of environmental variability and spawner characteristics on the recruitment of Baltic herring Clupea harengus populations. Mar Ecol Prog Ser 388:221-234

Casini M, Cardinale M, Arrhenius F (2004) Feeding preferences of herring (Clupea harengus) and sprat (Sprattus sprattus) in the southern Baltic Sea. ICES J Mar Sci 61: 1267-1277

> Casini M, Cardinale M, Hjelm J (2006) Inter-annual variation in herring (Clupea harengus) and sprat (Sprattus sprattus) condition in the central Baltic Sea: What gives the tune? Oikos 112:638-650

Casini M, Lövgren J, Hjelm J, Cardinale M, Molinero JC, Kornilovs G (2008) Multi-level trophic cascades in a heavily exploited open marine ecosystem. Proc R Soc B Biol Sci 275:1793-1801

Casini M, Hjelm J, Molinero JC, Lövgren J and others (2009) Trophic cascades promote threshold-like shifts in pelagic marine ecosystems. Proc Natl Acad Sci USA 106:197-202
Ciannelli L, Chan KS, Bailey K, Stenseth NC (2004) Nonadditive effect of the environment on the survival of a large marine fish population. Ecology 85:3418-3427

Cleveland WS (1993) Visualizing data. Hobart Press, Summit, NJ

EC (Council of the European Union) (2008) Council Regulation (EC) No 1322/2008 of 28 November 2008 fixing the fishing opportunities and associated conditions for certain fish stocks and groups of fish stocks applicable in the Baltic Sea for 2009. Off J Eur Union L 345:1-9

> Flinkman J, Aro E, Vuorinen I, Viitasalo M (1998) Changes in northern Baltic zooplankton and herring nutrition from 1980s to 1990s: top-down and bottom-up processes at work. Mar Ecol Prog Ser 165:127-136

Hänninen J, Vuorinen I, Hjelt P (2000) Climatic factors in the Atlantic control the oceanographic and ecological changes in the Baltic Sea. Limnol Oceanogr 45:703-710

Hastie TJ, Tibshirani RJ (1990) Generalized additive models. Chapman \& Hall, New York

Heath M, Scott B, Bryant AD (1997) Modelling the growth of herring from four different stocks in the North Sea. J Sea Res 38:413-436

> Hunt GL Jr, Stabeno P, Walters G, Sinclair E, Brodeur RD, Napp JM, Bond NA (2002) Climate change and control of the southeastern Bering Sea pelagic ecosystem. Deep-Sea Res II 49:5821-5853

Husebø Å, Slotte A, Stenevik EK (2007) Growth of juvenile spring-spawning herring in relation to latitudinal and interannual differences in temperature and fish density in their coastal and fjord nursery areas. ICES J Mar Sci 64: 1161-1172

ICES (2009a) Report of the Baltic Fisheries Assessment Working Group. ICES CM 2009/ACOM:07

ICES (2009b) Report of the Baltic International Fish Survey Working Group. International Council for the Exploration of the Sea. ICES CM 2009/LRC:05

Köster FW, Möllmann C, Hinrichsen HH, Wieland K and others (2005) Baltic cod recruitment: the impact of climate variability on key processes. ICES J Mar Sci 62:1408-1425

Laine P, Rajasilta M (1999) The hatching success of Baltic herring eggs and its relation to female condition. J Exp Mar Biol Ecol 237:61-73

Lehmann A, Krauss W, Hinrichsen HH (2002) Effects of remote and local atmospheric forcing on circulation and upwelling in the Baltic Sea. Tellus 54A:299-316

Litzow MA, Ciannelli L (2007) Oscillating trophic control induces community reorganization in a marine ecosystem. Ecol Lett 10:1124-1134

Mammen E (1993) Bootstrap and wild bootstrap for high dimensional linear models in resampling. Ann Stat 21: 255-285

Melvin GD, Stephenson RL (2007) The dynamics of a recovering fish stock: Georges Bank herring. ICES J Mar Sci 64: 69-82

> Möllmann C, Köster FW (2002) Population dynamics of calanoid copepods and the implications of their predation by clupeid fish in the Central Baltic Sea. J Plankton Res 24: 959-977

> Möllmann C, Kornilovs G, Fetter M, Köster FW, Hinrichsen HH (2003) The marine copepod Pseudocalanus elongatus, as a mediator between climate variability and fisheries in the Central Baltic Sea. Fish Oceanogr 12:360-368

Nissling A (2004) Effects of temperature on egg and larval survival of cod (Gadus morhua) and sprat (Sprattus sprattus) in the Baltic Sea: implications for stock development. Hydrobiologia 514:115-123

Renz J, Hirche HJ (2006) Life cycle of Pseudocalanus acuspes 
Giesbrecht (Copepoda, Calanoida) in the Central Baltic Sea: seasonal and spatial distribution. Mar Biol 148: $567-580$

Rönkkönen S, Ojaveer E, Raid T, Viitasalo M (2004) Longterm changes in Baltic herring (Clupea harengus membras) growth in the Gulf of Finland. Can J Fish Aquat Sci 61:219-229

Saltelli A, Chan K, Scott EM (2000) Sensitivity analysis. Probability and statistics series, John Wiley \& Sons, Somerset, NJ

Scheffer M, Carpenter SR (2003) Catastrophic regime shifts in ecosystems: linking theory to observation. Trends Ecol Evol 18:648-656

Shin YJ, Rochet MJ (1998) A model for the phenotypic plasticity of North sea herring growth in relation to trophic conditions. Aquat Living Resour 11:315-324

Shin YJ, Rochet MJ, Jennings S, Field JG, Gislason H (2005) Using size-based indicators to evaluate the ecosystem effects of fishing. ICES J Mar Sci 62:384-396

Stige LC, Lajus DL, Chan KS, Dalpadado P, Basedow SL, Berchenko I, Stenseth NC (2009) Climatic forcing of zooplankton dynamics is stronger during low densities of planktivorous fish. Limnol Oceanogr 54:1025-1036

Szypuła J, Ostrowski J, Margoński P, Krajewska-Sołtys A (1997) Food of Baltic herring and sprat in the years 19951996 in light of the availability of components. Bull Sea Fish Inst (Gdynia) 2:19-31

Submitted: December 11, 2009; Accepted: March 17, 2010
Tanasichuk RW (1997) Influence of biomass and ocean climate on the growth of Pacific herring (Clupea pallasi) from the south-west coast of Vancouver Island. Can J Fish Aquat Sci 54:2782-2788

- Vainikka A, Mollet F, Casini M, Gårdmark A (2009) Spatial variation in growth, condition and maturation reaction norms of the Baltic herring Clupea harengus membras. Mar Ecol Prog Ser 383:285-294

Voipio A (ed) (1981) The Baltic Sea. Elsevier, Amsterdam

- Watanabe Y, Dingsør GE, Tian Y, Tanaka I, Stenseth NC (2008) Determinants of mean length at age of spring spawning herring off the coast of Hokkaido, Japan. Mar Ecol Prog Ser 366:209-217

Wheeler JP, Purchase CF, Macdonald PDM, Fill R, Jacks L, Wang $\mathrm{H}$, Ye C (2009) Temporal changes in maturation, mean length-at-age, and condition of spring-spawning Atlantic herring (Clupea harengus) in Newfoundland waters. ICES J Mar Sci 66:1800-1807

Wilmers CC, Post E, Peterson RO, Vucetich JA (2006) Predator disease out-break modulates top-down, bottom-up and climatic effects on herbivore population dynamics. Ecol Lett 9:383-389

- Winters GH, Wheeler JP (1994) Length-specific weight as a measure of growth success of adult Atlantic herring (Clupea harengus). Can J Fish Aquat Sci 51:1169-1179

Wood SN (2003) Thin-plate regression splines. J R Stat Soc B 65:95-114

Proofs received from author(s): August 5, 2010 